\title{
USING SYSTEM DYNAMICS FOR SHORT LIFE CYCLE SUPPLY CHAINS EVALUATION
}

\author{
Enrico Briano \\ Claudia Caballini \\ Pietro Giribone \\ Roberto Revetria \\ DIPTEM - University of Genoa \\ Via Opera Pia, 15 \\ Genoa, 16145, ITALY
}

\begin{abstract}
This work is part of an Italian National Research Project embracing different aspects of a short life-cycle products supply chains: its modeling, its resiliency and its competitiveness. In fact, this particular kind of products, like fashion goods, toys or electronic devices, have different characteristics compared with long-medium life cycle products and this implies a quite different management as well as competitiveness factors to take into account. Starting from the modeling of a supply chain of this kind, utilizing the Powersim Studio Software implementing the System Dynamics methodology, with the goal of showing its behavior under specific scenarios, some vulnerability causes have been considered in order to make the supply chain more resilient. Finally, the competitiveness dynamics between two companies producing short life cycle items has been modeled and analyzed.
\end{abstract}

\section{INTRODUCTION}

The management of short life cycle products supply chains represents a challenging issue for companies which deal with these particular kind of goods. In fact products characterized by a short life cycle have different features that make them different from medium-long life cycle items. First of all, they are produced only over a limited period of time, which is usually smaller than one year, and after this time window they are completely dismissed from the market. The reason for that is that they soon become obs olete, usually not in terms of their physical features but in terms of brand popularity or evolving technologies. As a matter of fact, this type of products are usually emotional goods: customers buy them because of their huge emotional impact in terms of brand and popularity. This implies a different logic of selling: the emotional customers take for granted the technical quality of the product; what they do not take for granted is the closeness between the product and their aspirations, what they want to be - or be considered - by having that item. What the customers buy is above all the idea that surrounds the product, recalled by the brand and by visual details in which they identify themselves.

Moreover short life cycle products, such as fashion goods or electronic devices, whose shortness in terms of lifecycles is mainly determined by the high innovation rate of technology, follow particular purchasing and production logics that must be taken into careful attention.

Companies dealing with this particular type of products have to respond to the market, which is more and more uncertain and unpredictable, quicker than for normal life cycle goods. For this reason, the short life cycle supply chains must become more resilient, in order to reduce vulnerability and better overcome the occurrence of unpredictable damaging events. 


\section{Briano, Caballini, Giribone and Revetria}

By using the System Dynamics (SD) approach, the authors propose a simulation model devoted to analyze the behavior of a generic short life cycle supply chain. The SD approach has proved to be very effective in modeling and analyzing complex dynamics systems affected by non linearities, feedback loops and time delays, which significantly affect their whole system behavior (Sterman 2000). More specifically this methodology describes each systems, over a continuous time, in terms of stocks and flows. It represents also a powerful tool for formulating "What If" analysis in order to test different policies and helping decision makers in making the most proper choice.

In this research work, System Dynamics has been applied for two main reasons:

1. to model a short life cycle supply chain and study its behaviors under different scenarios, and to create a more resilient supply chain against unpredictable events, both of natural types (earthquakes, floods, etc.) and artificial (market changes, terrorist attacks, etc.), internal or external;

2. to study the competitiveness dynamics between two companies producing the same kind of short life cycle product, by identifying the competitiveness factors and with the final goal of determining which of the two enterprises is more successful under various scenarios implemented through the use of a proper decision cockpit.

More in particular, as far as regards the first point, the work focus is on the analysis of the supply chain behavior in case of an external threat (an earthquake), which strikes the main company raw materials supplier. The resiliency aspect is introduced considering the hypothesis of splitting the supply between two different suppliers, with each providing $50 \%$ of the total supply, showing that in this case the business continuity is guaranteed, although the production is halved.

The paper is divided as follows: section 2 describes the short life cycle supply chain dynamics and its behavior, while section 3, after a brief literature review (for more details see Briano, Caballini, and Revetria 2009), discusses how to make this supply chain more resilient, considering a supply disruption caused by an earthquake, showing the difference of relying on two main suppliers instead of only one. Section 4 provides the description of a SD model for the competitiveness analysis between two companies producing a similar short life cycle product; finally in section 5 some conclusion are presented.

\section{ANALYSIS OF A SHORT LIFE CYCLE SUPPLY CHAIN}

Among the different goals of this research, which has been conducted within a national Research Project funded by the Italian Ministry of University and Scientific Research, there is the aim of underlining the importance of simulation, and in particular of the System Dynamics methodology, for the study of short life cycle products' supply chains. This section focuses on the analysis of this kind of supply chains, whose management, according to Fisher (1997), is significantly different from the ones relative to a "normal" life-cycle, in several aspects. According to Szozda and Swierczek (2008), the main differences between the two typologies of supply chains are described in Table 1.

Table 1: Differences between short and long life cycle product supply chains

\begin{tabular}{|c|c|c|}
\hline Activity areas & Short life cycle product's supply chain & Long life cycle product's supply chain \\
\hline Planning & $\begin{array}{l}\text { - elementary planning } \\
\text {-accurate and separate } \\
\text { demand estimation for every product } \\
\text { and service, followed by computing } \\
\text { a single value for the company }\end{array}$ & $\begin{array}{c}\text { - global/general planning } \\
\text {-a single sales forecast is estimated } \\
\text { for the company; it is } \\
\text { possible with a robust range } \\
\text { of products }\end{array}$ \\
\hline Forecasting & $\begin{array}{c}\text { - Heuristic methods of forecasting } \\
\text { - Qualitative methods } \\
\text { - Forecast by analogy }\end{array}$ & $\begin{array}{l}\text { - Quantitative methods } \\
\text { - Statistical methods of forecasting }\end{array}$ \\
\hline
\end{tabular}




\begin{tabular}{|c|c|c|}
\hline Manufacturing & $\begin{array}{c}\text { - Flexible manufacturing systems } \\
\text { - Highly automated systems } \\
\text { - Manufacturing of a wide range } \\
\text { of products } \\
\text { - Outsourcing } \\
\text { - Hybrid manufacturing processes }\end{array}$ & $\begin{array}{l}\text { - Highly automated systems } \\
\text { - Production lines }\end{array}$ \\
\hline $\begin{array}{c}\text { Inventories } \\
\text { and warehouse } \\
\text { management }\end{array}$ & $\begin{array}{l}\text { - Manufacturing to order } \\
- \text { Reducing a number of stored materials } \\
\text { and products }\end{array}$ & $\begin{array}{l}\text { - Manufacturing for stock } \\
\text { - Purchasing of products for } \\
\text { Stock }\end{array}$ \\
\hline $\begin{array}{l}\text { Replenishment } \\
\text { (suppliers) }\end{array}$ & $\begin{array}{c}\text { - Global replenishment systems } \\
\text { - Long term contracts enabling flexible } \\
\text { time planning and ordered } \\
\text { quantities } \\
\text { - Reducing the number of suppliers to } \\
\text { those who offer the widest ranges } \\
\text { of raw materials } \\
\text { - Consolidation of orders from multiple } \\
\text { sources }\end{array}$ & $\begin{array}{c}\text { - Domestic and local suppliers } \\
\text { - Frequent changes of suppliers } \\
\text { - Long delivery times } \\
\text { - Large number of suppliers } \\
\text { - Traditional way of communication, } \\
\text { no common and } \\
\text { shared information systems }\end{array}$ \\
\hline
\end{tabular}

A short life cycle product requires a more responsive, flexible and agile organization compared to a long life cycle one. A more accurate and precise demand forecasting is required because it is concentrated in a limited period of time and it must be accurately followed by the production in order neither to result in products shortage nor in overstock, difficult to get rid of. Regarding this last aspect, considering the limited life duration of the product, it is recommended a precautionary approach, especially at the end of the life cycle, in order not to remain with a stock of unsold items, that can erode the company profit.

Comparing the demand pattern for a short life cycle scenario with a long life cycle one, some significant differences must be noticed: as a matter of fact, the latter presents a higher variance (a more spread demand pattern) distributed around a lower peak (left curve of Figure 1) while, on the contrary, short life cycle products, show a more shrunk curve that means a lower variance, with a higher peak (right curve of Figure 1). This difference is due to the fact that a short lifecycle product have to be sold in a limited period, because of different causes: obsolescence (like for electronic devices) or fashion trends or because they must be sold under particular events, such as a Football World Cup Championship or Olympic Games. This shrunk time window implies the need of intensive marketing campaigns and an efficient supply chain, in order to sell all the inventory during this time bucket.
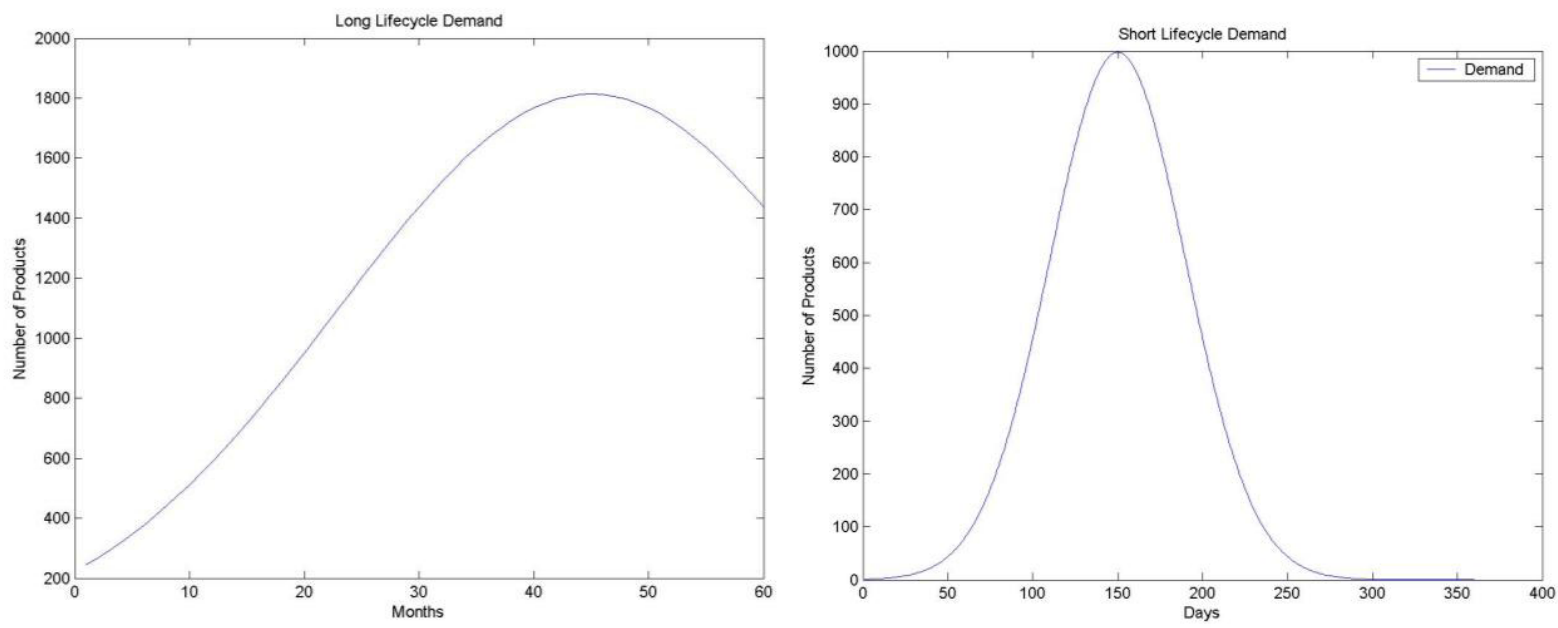

Figure 1: Typical demand patterns for long (left curve) and short (right curve) lifecycle products (Source: Briano et al. 2010a) 


\section{Briano, Caballini, Giribone and Revetria}

After analyzing the peculiarities of the short life cycle supply chains demand pattern, a conceptual model that takes into account these features has been designed. As shown in Figure 2, a three steps supply chain has been considered: items are processed in two different sequential production steps, each one characterized by different production times. The first production step transforms raw materials into halffinished products (Work In Progress - WIP), whose desired value is a function of the safety stock and of the future forecasting. Semi-finished items pass through another production machine, characterized by a different lead time (in this case there is a fixed delay, as it is shown by the delay symbol in Figure 2), which transforms them into finished products that are stored in a warehouse waiting to be shipped to the customers.

Raw materials are ordered from one supplier, although the company could address more than one supplier, in order to protect itself from eventual stops in the supply, but this scenario will be analyzed in detail in the following section.

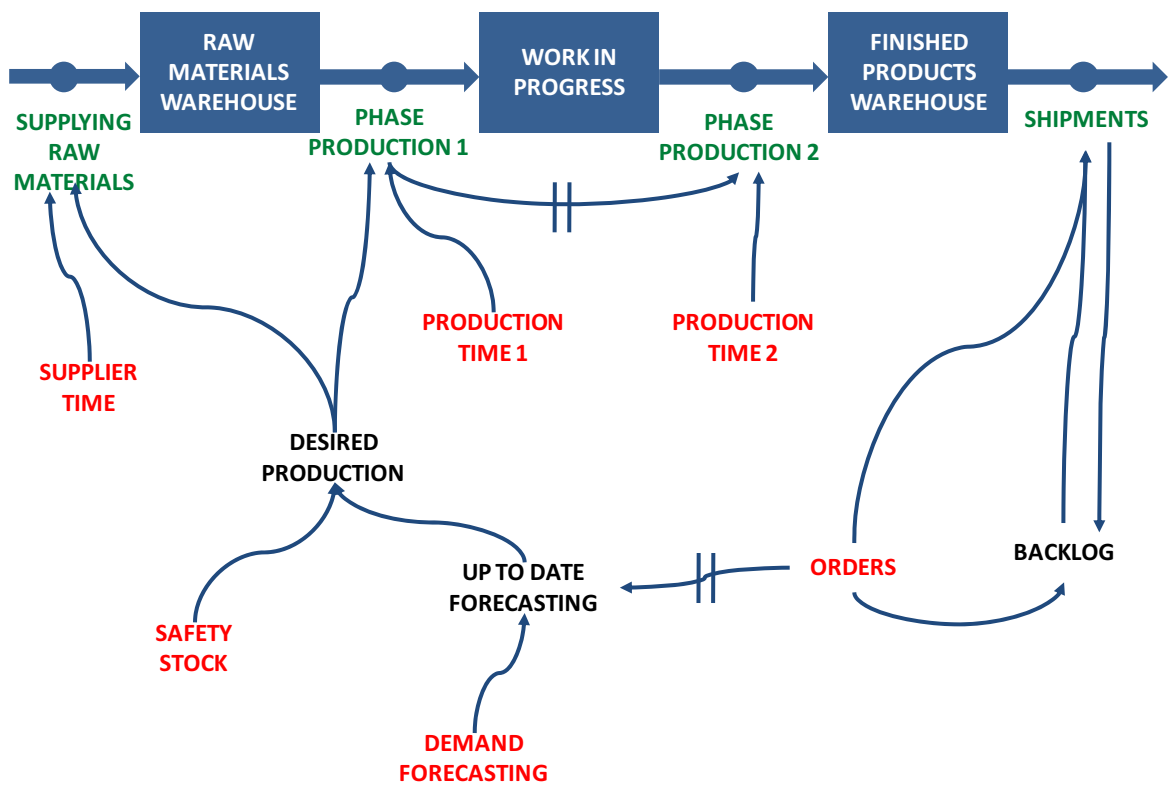

Figure 2: The conceptual model (Source: Briano et al. 2010a)

The demand forecasting is given as input to the model and it is continuously updated considering the gap between a double exponential smoothing made on actual sales and the forecasted demand (Wu et al. 2006); for the accuracy of the demand itself, and its particular kind of modeling, this conceptual model is particularly suitable for short-life cycle products rather than longer ones.

Considering all these aspects, the System Dynamics simulation model has been implemented in order to better understand how the system behavior changes over time modifying some of its characteristic parameters, like lead times, warehouse initial values or the demand pattern (in other words, giving a more or less accurate shape of the demand forecasting distribution as input) and what are the impacts of these changes on the amount of sold items and, consequently, on the total company profit (Kamath and Roy 2007).

After these analysis, the focus of the research has been shifted on how to modify this supply chain in order to make it more resilient, able to guarantee the business continuity even in the case of an external threat provided by an earthquake that strikes a raw materials supplier.

\section{BUILDING A RESILIENT SUPPLY CHAIN WITH SYSTEM DYNAMICS}

In the last years, catastrophic events such as the terrorist attacks of September 11 2001, the Katrina hurricane or the Middle East wars sensibly modified the concept of preparation to disasters. Consequently the 


\section{Briano, Caballini, Giribone and Revetria}

supply chain vulnerability has become a particularly important issue for many companies, generating a big challenge in managing and mitigating the various risks to which they are exposed, through the creation of more resilient supply chains, able to opportunely and efficaciously face unexpected events.

Some authors provided definitions and recommendations about supply chains vulnerabilities and resiliency and how to face this issue properly. The most important works regarding this topic have been developed by the following subject matter experts: Bjorn Egil Asbjørnslett, co-ordinator of the "Resilient Global Logistics" project, and Marvin Rausand, Professor in reliability engineering, who described the steps to be adopted for a vulnerability analysis in their work "Assess the vulnerability of your production system"(1997); Martin Christopher and Yossi Sheffi - full professors respectively at Cranfield University and Massachusetts Institute of Technology and authors of many works focusing on Supply Chain Resiliency, like for instance "Building the resilient supply chain" (2004) for the former and "Supply Chain Management under the Threat of International Terrorism" (2001) for the latter - that classified the major risks for a company in macro categories depending on their source and provided important guidelines to make a supply chain more resilient.

Starting from the studies provided by these authors, the SD short life cycle supply chain model has been modified in order to make it able to cope with an unpredictable event.

As first step the vulnerability analysis methodology proposed by Asbjornslett and Rausand (1997), has been applied:

1. to develop an assessment scenario, listing threats and the probabilities correlated to every potential risk scenario, and investigate if there are contingency measures or risk mitigation initiatives in action;

2. to analyze, in a quantitative way, the factors detected in the previous point, classifying threats and scenarios on the basis of the criticalities determined in terms of impact on human, environmental, commercial and real estate resources.

3. Report threats in an appropriate vulnerability map, which can be implemented in different ways.

4. Select critical events in the vulnerability map and then explain how they should be faced in order to reduce the probability of the risky events and their consequences.

After this analysis, all the possible risks have been classified into some categories using the methodology in Christopher and Towill (2002):

- internal risks regarding the interruption of a process or to the erroneous application of norms and procedures;

- external risks regarding demand or supply;

- environmental risks, related to events that occur outside the supply chain, but that affect it.

In this work, an environmental risk has been chosen, considering the case of a natural threat - an earthquake - that strikes the raw material supplier, making not possible the regular procurement flow. In order to prevent this effect, the model has been modified by duplicating the supply flow, meaning that the companies can rely on two different vendors, as suggested by Yossi Sheffi (2005a) regarding the best supply strategy.

Figure 3 implements the conceptual scheme provided in Figure 2 by utilizing the Powersim Studio $7^{\mathrm{TM}}$ software, so the two figures represent the same model, except for the revenues and cost part, that is only shown in Figure 3. This tool has been chosen because of its flexibility and completeness, and for the possibility of integrating it with databases and ERP systems, such as SAP ${ }$. The flow colored in red in Figure 3 has been added only in the resilient case. While after the earthquake occurrence, there is a permanent interruption of the raw material flow, in the resilient configuration, only one of the two flows is canceled, guaranteeing a supply continuity. 


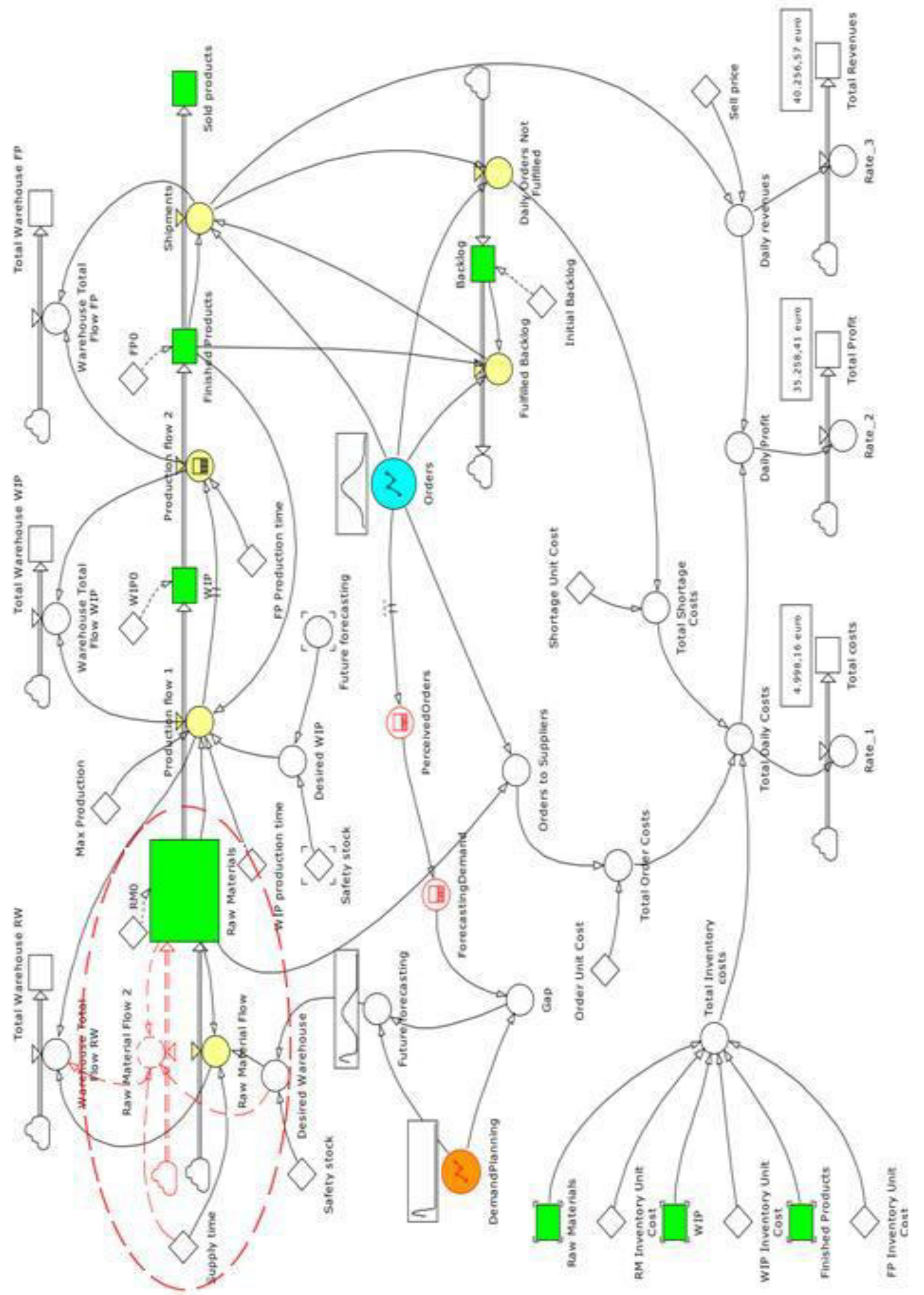

Figure 3: The SD supply chain model in Powersim 
For a proper assessment of the earthquake impact on the supply chain, a comparative analysis of the total revenues, costs and profits, before and after the disruption, has been carried out. Figure 4 shows the behavior of the total revenues, costs and profits before (left graph) and after the earthquake (right graph), in case of a single supplier procurement. As can be seen, before the disruption, total revenues and profits are continuously growing, because the more items are sold, the higher are the revenues and, consequently, profits. On the contrary, a significantly different behavior is found after the earthquake blocks the raw materials supplier: total costs grow rapidly in the initial phase because of the lack of materials and, for the same reason, total revenues reservoir level remains constant because no more items can be sold. A similar behavior is found for total profits, being them the difference between total revenues and costs. As a consequence, a non resilient supply chain, which does not contemplate the hypothesis of a redundancy on the supply flow, represents a serious danger for the company's business, because it is not able to always fulfill the products demand.
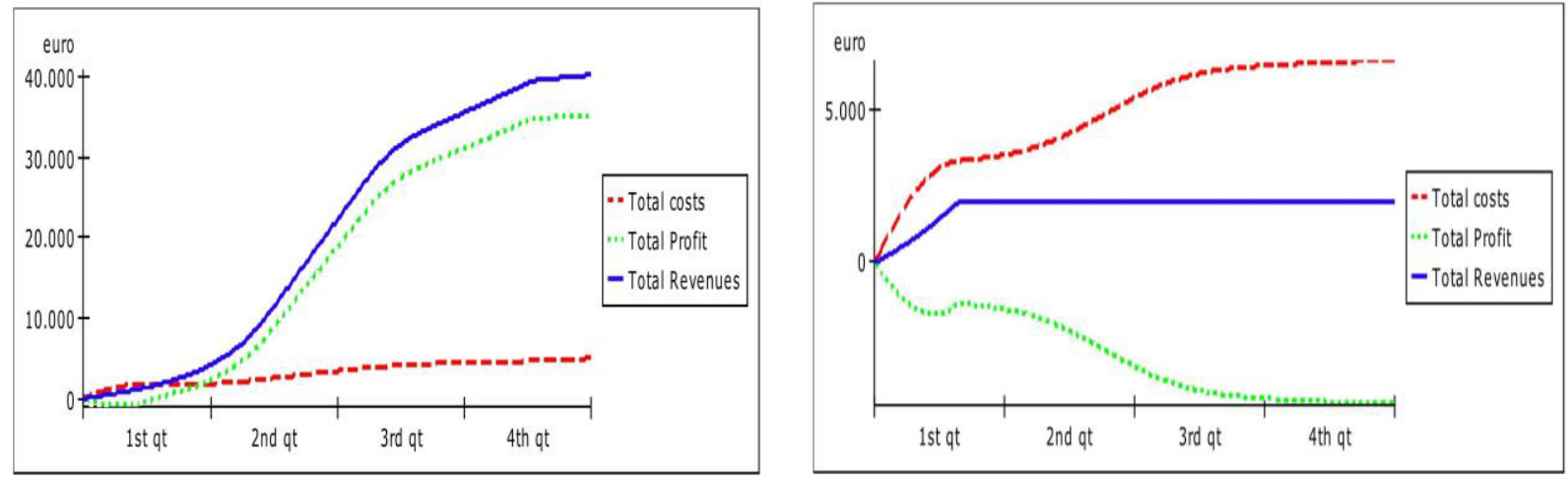

Figure 4: Total costs, revenues and profits before (on the left) and after the earthquake (on the right)

On the contrary, taking into account the Yossi Sheffi (2005b) resiliency principles by splitting the raw material supply among two main different vendors, the company behavior is pretty different. In fact, even after the disruption on one of the raw material supplier, the production continuity is still guaranteed, even if the company works at only the $50 \%$ of its capacity, with a halved production. The SD model changes adding the another raw material flow (in red), as shown in Figure 3.

Analogously to the first supply chain, also for the resilient enterprise an economic comparison, before and after the disruption, has been considered: Figure 5 left graph represents the situation before the earthquake while the right graph shows the various trends after the disruption. These graphs show that there are no substantial differences before and after the disaster, except for different variables' values, which are of course higher before the earthquake when the company can benefit of a complete raw material procurement. Instead, in the lower graph, the company is able to guarantee the production continuity only at the $50 \%$ of its capacity, because its procurement has been halved.

In conclusion, a resilient enterprise is able to guarantee the production also in the case of an external risk - as an earthquake - and, although the total profit has been halved, there is not a dramatic change in the company economic trend. On the contrary, without considering a redundancy on the procurement flow, the production is stopped causing a negative economic impact on the company profit.

\section{THE COMPETITIVENESS ANALYSIS ABOUT SHORT LIFE CYCLE SUPPLY CHAINS}

Supply chains, resilient or not, are subjected to the sales behavior, which is in turn affected by the competitiveness of the market; in the following section the competitiveness dynamics regarding two companies producing short life cycle products is analyzed and compared, properly identifying and weighting all the factors that affect it. 

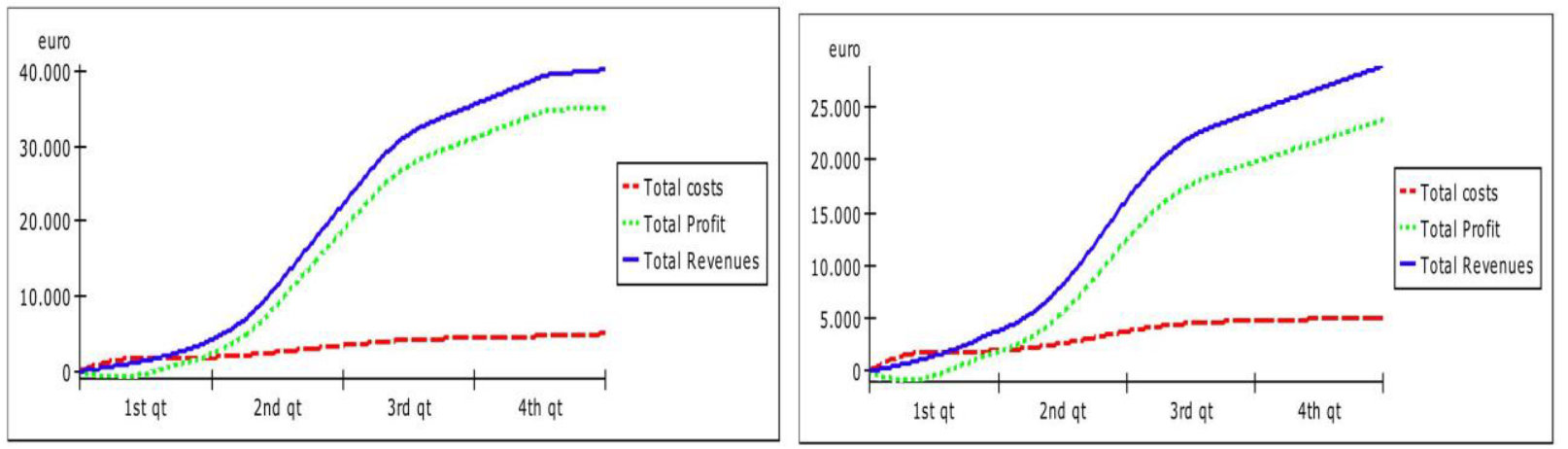

Figure 5: The resilient organization revenues, costs and profits before (on the left) and after the disruption (on the right)

Competitiveness is a critical issue in the market analysis context, especially in the current globalization era. In fact, it has a great impact on the sales pattern and it is composed of various parameters, which have been constantly studied and monitored; this is especially true for short life cycle products, which are often subjected to emotional aspects, technology level and brand affection. Also the concept of attractiveness is complex to be analyzed, being determined by factors that change not only in relation to goods, merchandise or services type, but also to emotional aspects that are part of what is known as the sphere of the psychology of purchase.

In this work, the interaction between two competitors, called for sake of simplicity A and B, has been studied. The idea is to evaluate, basing on some typical competitiveness parameters, which product is more competitive in the market against the other one, guaranteeing a higher value of sales and, consequently, a more positive impact on its supply chain; in fact, as seen in section 2, sales affect the demand forecasting and, as a consequence, the production level of the whole supply chain.

The different parameters taken into account in this competitiveness analysis have been associated to specific weights: the bigger the weight value, the more important the relative competitiveness factor; the total competitiveness of the product is given by the sum of the scores registered by the product for each factor multiplied by its weight.

Especially in the case of short life cycle products, when the projection of demand is made over a limited time, the competitiveness or attractiveness of products in respect to the market, is difficult to determine because it is related to a process depending not only on quantitative data but also on the feelings of the buyers/consumers, which are not necessarily rational or in line with the quality of the specific good or service. Regarding the quantitative factors, the most significant and immediate ones are the retail price, the market share, the number of sales in a defined period of time.

The overall quality, that represents the consumer perception of the product-service as a whole, represents a qualitative factor, more difficult to estimate and quantify because it is in relation to the characteristics that each customer considers to be essential.

In order to compare the quantitative and qualitative factors identified, the Matrix approach proposed by General Electric, better known as the Directional Policy Matrix (DPM) developed jointly with McKinsey \& Company, has been used, resulting in the most suitable methodology to make this kind of analysis. The basic concept of this matrix is to relate, using a criterion of "scoring" and weighing of variables, all the significant factors which are not directly comparable (Collis, Campbell, and Goold 1999).

Following the DPM structure, a SD model (Figure 6) has been developed. 
Briano, Caballini, Giribone and Revetria

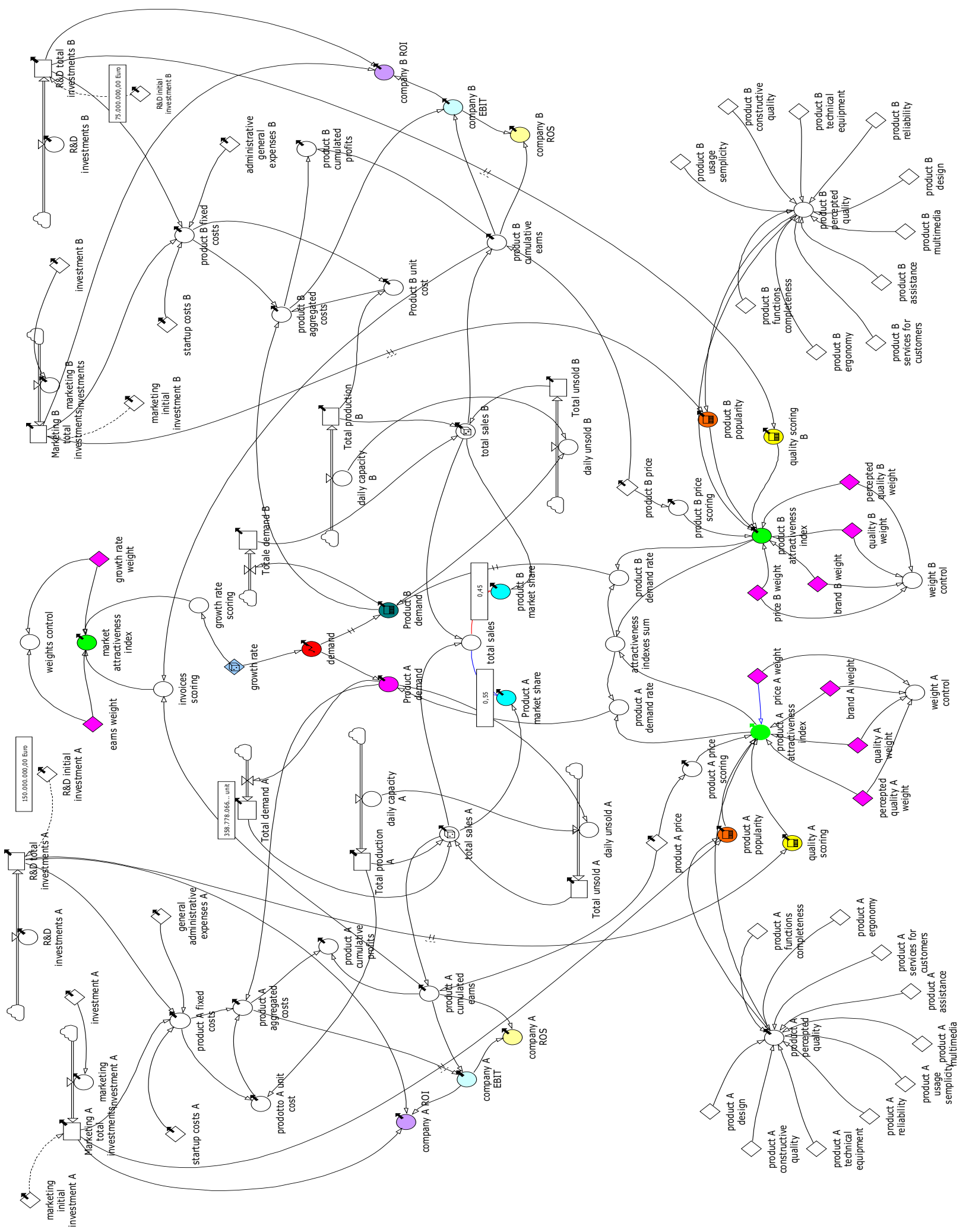

Figure 6: The SD model regarding the competitiveness between two companies producing short life cycle products 


\section{Briano, Caballini, Giribone and Revetria}

In order to determine the attractiveness indexes of each product, the following step-by-step procedure has been used:

1. choose the variables most related to the success of the product in the market;

2. evaluate, for each of the variables chosen, the "direction" of the correlation. There are in fact variables which grow together with the attractiveness of the considered target market, and variables that behave exactly in the opposite way (consider, for example, price);

3. evaluate the "weight" of the variables, considering their relative importance within the competitive scenario. For each of them, an increasing value is assigned according to the particular type of the customer opinion that may be poor, sufficient, good or excellent (i.e. poor $=0$, sufficient 0.25 , good $=0.5$, excellent $=1$ );

4. calculate, on the basis of the previous steps, a weighted index devoted to provide a synthetic evaluation of the attractiveness of each product, considered referring to the specific project of internationalization.

The attractiveness weighted index is determined applying, for each product under consideration, the following formula:

$$
I=\frac{\left(x_{1} p_{1}\right)+\left(x_{2} p_{2}\right)+\ldots+\left(x_{n} p_{n}\right)}{\left(p_{1}+p_{2}+\ldots+p_{n}\right)}
$$

where $I$ represents the attractiveness weighted index, $x_{1} \ldots x_{n}$ are the $n$ variables considered and $p_{1} \ldots p_{n}$ their weights.

The product attractiveness index is characterized by different significant parameters: the product perceived quality, the brand popularity, the intrinsic quality and the product price: the first parameter characterizing the product attractiveness is the quality perceived by consumers. This aspect, together with the price, is decisive for the success of a certain product. For this reason, it is important for companies to invest in the optimization of tools able to promptly gather information devoted to improve the product itself and so the customer satisfaction. The perceived quality is affected by a series of characteristics, like product design or reliability.

Another feature considered in the model is the brand popularity: this is the image that a company has built over time, ensuring the retention of customers who value its brand. Also for this feature a scoring criterion affecting the overall competitiveness of the product has been determined.

The variables defining the intrinsic quality of a product are generally the materials' capability to last over time and the capability of the product to maintain its utility.

The last key factor determining the attractiveness index is the product price, which is, together with the perceived quality, probably the most important one to decree the product success; price is in fact considered one of the "4P" (product, price, place, promotion), that is one of the variables of the marketing mix. The company makes pricing decisions when a new product is launched, when an existing product needs a change of the price, or when it has to react to changes in the price of the competitors. The pricing of a product is influenced by internal factors (marketing objectives and costs) and external factors (market and demand, competition, fluctuations in the exchange rate and anti-dumping legislation).

Another key factor to take into account, apart from the product attractiveness, is the attractiveness of the market, which is defined uniquely by the total revenues generated by the two companies operating in the market over the time period of a year, multiplied by the expected growth rate of the same sector; this makes possible to give an estimate of what are the potential revenues for the following year.

In the SD model, the market attractiveness index has been defined in the same manner as the one for the products: 


$$
I=\frac{\left(x_{1} p_{1}\right)+\left(x_{2} p_{2}\right)+\ldots+\left(x_{n} p_{n}\right)}{\left(p_{1}+p_{2}+\ldots+p_{n}\right)}
$$

where the variables considered refer to the two companies total revenues and their expected growth rate.

The model also considers the calculation of economic performance indicators, like ROI (Return on Investment), ROS (Return on Sales) and EBIT (Earning Before Interests and Taxes) and, moreover, a decision cockpit has been built, in order to help decision makers to formulate "What If" analysis varying the parameters and performing different scenarios.

The SD model has been used to perform three different competitiveness scenarios: in all of them, the company A is a leader in its market while the role of company B changes continuously: in the first scenario company B is also a leader, while in the second one it adopts the strategy "follow the leader" (aligned with the decisions of the company A) and in the third one it adopts an "efficient production" strategy, devoted to follow the leader directives, but trying to optimize the productive process (typical of a company with a low market slice).

The results provided as output of the model in the three different scenarios highlight the importance, in order to grow the market quota for company B, to adopt the leader strategy, hindering the company A predominance. However, this implies for company B significant efforts in terms of investments that could be also very risky. On the other hand, using the other two strategies (follow the leader and efficient production), the company B records higher values of ROI and ROS and, especially in case of "follow the leader" strategy, also an higher operative result, making these alternatives less risky and economically preferable compared to the leader strategy.

\section{CONCLUSION}

This work aimed to provides a description and analysis regarding different important aspects of short life cycle products supply chains, utilizing the System Dynamics approach and simulation. After underlining the main differences between a short life cycle product supply chain and normal ones, the dynamics and the behavior of the former have been studied in more detail, evaluating a real case study with a three-step production (raw materials, semi- finished products and finished products).

In a second step, the resiliency concept has been introduced, considering a particular type of external threat: an earthquake that strikes the raw material supplier. The obtained results show that the resilient organization guarantees the business continuity thanks to its redundancies, versus the non resilient one, which is not able to satisfy the demand in case of disruption.

Finally, in the last part of the paper the attention is focused on the competitiveness and attractiveness aspects between two companies producing short life cycle products, by utilizing another SD model and the approach provided by the Directional Policy Matrix.

\section{ACKNOWLEDGMENTS}

The authors would like to thank Lorenzo Munzi and Andrea Ziliotto for their useful support to this research.

\section{REFERENCES}

Asbjørnslett, B. E., and M. Rausand. 1997. Assess the vulnerability of your production system (No. 97018): Norwegian University of Science and Technology.

Briano, E., C. Caballini, and R. Revetria. 2009. Literature review about supply chain vulnerability and resiliency, Proc. 8th WSEAS International Conference on SYSTEM SCIENCE and SIMULATION in ENGINEERING. Genova, Italy, October 17-19.

Briano, E., C. Caballini, P. Giribone, and R. Revetria. 2010a. Using a System Dynamics Approach for Designing and Simulation of Short Life-Cycle Products Supply Chain. Proccedings of the $4^{\text {th }}$ WSEAS 


\section{Briano, Caballini, Giribone and Revetria}

International Conference on Computer Engineering and Application (CEA'10), Harvard University, Cambridge MA, January 27-29.

Briano, E., C. Caballini, P. Giribone, and R. Revetria. 2010b. Design and Simulation of a Short Life Cycle Product Supply Chain: A System Dynamics Approach. Proceedings of IASTED International Conference on Modeling, Identification and Control (MIC 2010), Innsbruck, Austria, February 15-17.

Christopher M., and D. Towill. 2002. Developing Market Specific Supply Chain Strategies. International Journal of Logistics Management 13(1):1-13.

Christopher, M., and H. Peck. 2004. Building the resilient supply chain. International Journal of Logistics Management 15(2):1-14.

Collis, D.J., A. Campbell, and M. Goold. 1999. Harvard Business Review on Corporate Strategy. Harvard Business Press, ISBN 978-1578511426.

Fisher, M.L. 1997. What is the Right Supply Chain for Your Product? Harvard Business Review, MarchApril, 105-116.

Kamath, N.B., and R. Roy, 2007. Capacity augmentation of a supply chain for a short lifecycle product: A system dynamics framework, European Journal of Operational Research 179:334-351.

Sheffi, Y. 2001. Supply Chain Management under the Threat of International Terrorism. International Journal of Logistics Management, 12(2):1-11.

Sheffi, Y. 2005a. Building a Resilient Supply Chain. Harvard Business Review Supply Chain Strategy $1(8): 1-11$.

Sheffi, Y. 2005b. The Resilient Enterprise - Overcoming Vulnerability for Competitive Advantage. Cambridge, MA: MIT Press.

Sterman J. 2000. Business Dynamics. Thinking and Modeling for a Complex World. Irwin/McGraw-Hill.

Szozda, N. and A. Swierczek, 2008. The success factors for supply chains of a short life cycle product. Total Logistic Management 1:163-173.

Wu, S.D., B. Aytac, R.T. Berger, and C.A. Armbruster. 2006. Managing Short Lifecycle Technology Products for Agere Systems, Interfaces 36(3):234-247.

Wu, S.D., and B. Aytac, Characterization of demand for short life-cycle technology products, Report No. 07T-005.

\section{AUTHOR BIOGRAPHIES}

ENRICO BRIANO was born in 1980, and completed his studies in Management Engineering at the University of Genoa in November 2004, when he took the degree. In March 2010 he got his PhD in Mathematical Engineering and Simulation at the University of Genoa and cooperates with DIPTEMDepartment of Production Engineering, Thermoenergetics and Mathematical Models in the same University. He is partner of DIP consortium, a company also involved in simulation. His e-mail address is <enrico.brianodunige.it>.

CLAUDIA CABALLINI was born in Cremona (Italy) in 1980. In 2004 she obtained her degree in Management Engineering (5 years) at the Faculty of Engineering of Genoa University (Italy) with full marks. From February to April 2003 she took part at the international program IEPAL - Intensive Educational Program in Advanced Logistic, promoted by DIP - Production Engineering Department of Genoa University, in collaboration with the Stevens Institute of Technology, Boston College and University of Florida Centre of Simulation. Since January 2007 she is working at CIELI - Italian Centre of Excellence in Integrated Logistics - of Genoa University as a $\mathrm{PhD}$ student, where she also actively collaborate with DIPTEM. Her e-mail address is <claudia.caballini@unige.it $>$.

PIETRO GIRIBONE earned his degree in mechanical engineering at the University of Genoa and is Full Professor of "Mechanical Plants" and "Industrial Plants" at DIPTEM (Department of Production Engineering, Thermoenergetics and Mathematical Models) in Genoa University. Since 1979 he has specialized in experimental design applications for industrial simulators. In 1983, together with Prof. Mosca, he 
created an industrial simulation work group at the University of Genoa and since that time has been involved with many different technical, economical and environmental developments in the plant engineering sector. He is a member of the International Committee of the IASTED and the Board of Directors of ANIMP. His e-mail address is pieroditim.unige.it>.

ROBERTO REVETRIA earned his degree in mechanical engineering at the University of Genoa and completed his master thesis in Genoa Mass Transportation Company developing an automatic system integrating ANN (Artificial Neural Networks) and simulation with an ERP (Enterprise Resource Planning) for supporting purchasing activities. He completed is $\mathrm{PhD}$ in Mechanical Engineering in 2001 defending his Doctoral thesis on "Advances in Industrial Plant Management" by applying Artificial intelligence and Distributed Simulation to several industrial cases. Since 1998 he is active in Distributed Simulation by moving US DoD HLA (High Level Architecture) Paradigm. He is currently involved, as associate professor, in the DIPTEM of Genoa University. He is teaching Modeling \& Simulation, VV\&A, Distributed Simulation (HLA), Project Management in Master Courses Worldwide and he is teaching Industrial Plants Design and Maintenance Management in University of Genoa Masters' Courses. He is member of SCS, IASTED, ACM, ANIMP, AICE, MIMOS and Liophant Simulation Club. His e-mail address is <roberto.revetrialunige.it>. 